TITLE:

\title{
Modulation of Th1/Th2 balance by infliximab rescues postoperative occurrence of small-intestinal inflammation associated with ulcerative colitis.
}

\section{$\operatorname{AUTHOR}(S)$ :}

Akitake, Reiko; Nakase, Hiroshi; Tamaoki, Masashi; Ueno, Satoru; Mikami, Sakae; Chiba, Tsutomu

\section{CITATION:}

Akitake, Reiko ...[et al]. Modulation of Th1/Th2 balance by infliximab rescues postoperative occurrence of small-intestinal inflammation associated with ulcerative colitis.. Digestive diseases and sciences 2010, 55(6): 1781-1784

\section{ISSUE DATE:}

2010-06

\section{URL:}

http://hdl.handle.net/2433/126698

\section{RIGHT:}

The original publication is available at www.springerlink.com; この論文 は出版社版でありません。引用の際には出版社版をご確認ご利用くだ さい。; This is not the published version. Please cite only the published version. 
Title: Modulation of Th1/Th2 balance by Infliximab Rescues Postoperative Occurrence of Small-Intestinal Inflammation Associated with Ulcerative Colitis

Running title : Effect of IFX on Small Intestinal Inflammation

Reiko Akitake, MD, Hiroshi Nakase, MD, PhD, Masashi Tamaoki, MD, Satoru Ueno, MD, Sakae Mikami, MD, Tsutomu Chiba, MD, PhD

Department of Gastroenterology and Hepatology, Graduate School of Medicine Kyoto University, Kyoto, Japan

Corresponding to: Hiroshi Nakase, $\mathrm{MD}, \mathrm{PhD}$

Department of Gastroenterology and Hepatology, Graduate School of Medicine Kyoto University.

54 Shogoin Kawahara-cho, Sakyo-ku, Kyoto, 606-8507, Japan

Tel: +81-75-751-4319

FAX: $+81-75-751-4303$

E-mail: hiropy_n@kuhp.kyoto-u.ac.jp

\section{Key Words}

ulcerative colitis, small-intestinal inflammation, infliximab, Th1/Th2 balance 
Grant: This work was supported by Grant-in-aid for Scientific Research 16017240, 15209024, 15659169, and 18209027 from the Ministry of Education, Culture, Sports, Science, and Technology of Japan, and Grant-in-Aid for Research on Measures for Intractable Diseases, and Research on Advanced Medical technology from the Ministry of Health, Labor, and Welfare, Japan and the Kato Memorial Trust for Nambyo Research 


\section{Introduction}

In general, ulcerative colitis (UC) is defined as idiopathic inflammation limited to colorectum except backwash ileititis and postcolectomy pouchitis. However, UC is also considered to be a systemic disease because of not only colonic inflammation but also joint, skin, and acute hepatic involvement. Recently, there are several reports UC patients with gastroduodenitis or enteritis [1-4]. Cases of gastroduodenitis or enteritis associated with UC are clinically rare but important issue for gastroenterologists in the point of no optimal treatment established. Here, we report a case of the postoperative occurrence of small-intestinal inflammation associated with UC successfully treated with infliximab. 


\section{Case report}

A 19-year old female was referred to our hospital in January 2007 because of severe abdominal pain and hematochezia. Four years before admission, she had been diagnosed with ulcerative colitis (pancolitis type) both endoscopically and histologically. She was treated with oral salazosulfapyridine and corticosteroids. However, she required a dose-up of corticosteroids, mesalamine and granulocytapheresis because she did not achieve remission. But in January 2007, the patient was readmitted to our hospital because of exacerbation of her UC. After the additional treatment with tacrolimus and azathioprine (AZA), her symptom was improved and corticosteroids was gradually tapered off and completely stopped after 5 months. But, the patient was readmitted because of relapse of her UC in September 2007. On admission, the body temperature was $37.3 \mathrm{C}^{\circ}$ and laboratory data showed slight anemia and mild elevation of C-reactive protein (CRP) (WBC $6300 / \mathrm{mm}^{3}, \mathrm{RBC} 374 \times 10^{4} / \mathrm{mm}^{3}, \mathrm{Hb} 11.8 \mathrm{~g} / \mathrm{dl}, \mathrm{Ht}$ $36.2 \%$, CRP $0.4 \mathrm{mg} / \mathrm{dl})$. Colonoscopy disclosed diffuse edema, loss of vascular pattern and easy-bleeding from the rectum up to cecum. The serology test, immunohistochemistry and mucosal PCR were negative for cytomegalovirus. Both esophago-gastro-duodenoscopy (EGD) and radiographic visualization of small intestine revealed normal findings. Histological examination showed no infiltration of 
inflammatory cells in gastroduodenal mucosa. Since she repeated flare-up of her UC despite the use of immunomodulators, proctocolectomy with IPAA (ileal-pouch-anal anastomosis) and a temporary diverting ileostomy was performed in the end of September. Histological diagnosis of the colectomy specimen was compatible with pancolitis UC, and no inflammation and granuloma was not detected in the terminal ileum. The postoperative course was uneventful and her condition was stable without any medication.

In February 2008, however, she was admitted again because of frequent vomiting and severe epigastralgia at 65 days after colectomy. EGD revealed edema, granularity in the duodenal bulb and the second portion of duodenum (Figure 1). Histological examination taken from the duodenum showed neutrophil infiltration in the submucosa and cryptisis with no findings of non-caseous granuloma (Figure 2). Also, neither villous atrophy nor crypt hypertrophy was observed in the biopsy specimen, which suggested no possibility of celiac disease or autoimmune enteropathy of her disease. Immunohistochemistry and serological test was negative for H.pylori. Stool culture was also negative for Clostridium difficile. Taken together, we diagnosed her having duodenitis associated with UC. Her abdominal pain deteriorated despite the prompt treatment with mesalamine. An abdominal CT revealed the marked distention and wall 
thickening and edema of small intestine (Figure 3), which was suggestive of the occurrence of small-intestinal inflammation associated with UC. Additionally, pouch endoscopic findings revealed diffuse edema, loss of vascular pattern, and small erosions with pus in the pouch. Histological findings of biopsy specimen were compatible with pouchitis. Infliximab (IFX) $(5 \mathrm{mg} / \mathrm{kg})$ was promptly initiated. She rapidly responded to this treatment, and EGD at 109 days after administration of IFX revealed significant improvement of duodenitis when seen in June 2008 (Figure 4). Pouch endoscopy also revealed improvement of her pouchitis. We performed intracellular cytokine assay with peripheral CD4 T cells before and after IFX therapy. The ratio of T-helper (Th) 1 (IFN- $\gamma$ ) /Th2 (interleukin (IL)-4) was increased (31.7) at two weeks after IFX therapy compared to that before (14.5). She was in clinical remission with maintenance therapy of IFX. 


\section{Discussion}

Gut inflammation in UC has been considered to limited to the large bowel. Several cases of UC with gastrointestinal involvement have been reported [5-7]. Rubstein et al. reported 5 UC cases with duodenal and jejunal involvements [7]. Hori et al reported the prevalence (19/250: 7.6\%) and significant risk factors (pancolitis and a lower dose of predonisolone) of gastroduodenitis associated UC by performing prospective esophagogastroduodenoscopy for 250 Japanese patients with UC [8]. Since the endoscopic features mimicking those of colon are sometimes helpful for making diagnosis of gastroduodenitis related to UC, EGD is available for examining whether gastroduodenitis would occur in patients with UC after colectomy $[9,16]$. It was reported that duodenitis associated with UC occurred after colectomy tends to be accompanied by pouchitis as in our present case [9]. These reports suggested that both EGD and pouch endoscopy should be performed when patients with UC taking colectomy complain of abdominal symptoms.

Thus, much attention is focused on UC patients with gastroduodenitis or enteritis, although the etiology is still unknown. Recently, Gooding et al. reported 8 cases of idiopathic small-intestinal inflammation after colectomy for UC including their own 
case [9]. In seven out of eight cases, immunosuppressive therapies such as

corticosteroids or azathioprine were effective. Finally, they concluded that patients with idiopathic small intestinal inflammation should be treated by immunosuppressants promptly after the diagnosis was made because these patients responded well to immunosuppressive therapies.

However, no standard therapy on patients with small intestinal inflammation associated with UC has been established yet. In present case, our patient was promptly treated with the combination of IFX and three days methylprednisolone at diagnosis of panenteritis after colectomy. The reason why we administered IFX alternative to immunomodulators is due to that she had experienced flares up of her UC several times before colectomy irrespective of using immunomodulators such as AZA and tacrolimus. At present, she kept clinical remission with maintenance therapy of IFX after completely tapering off corticosteroid.

It is well known that IFX, a chimeric monoclonal antibody directed against tumor necrosis factor- $\alpha$, is effective for patients with Crohn's disease and UC [10-12]. However, whether IFX can be effective for UC patients with small intestinal inflammation after colectomy remains unclear. In present case, interestingly, her 
abdominal symptoms subsided with the increase of the Th1/Th2 ratio of peripheral CD4 T cells after administration of IFX. This intracellular cytokine data suggested that the pathophysiology of small intestinal inflammation occurred after colectomy in patients with UC might be associated with a Th2 cytokine phenotype. Our several reports showed that skewing toward Th1 cytokine profile could lead to reduction of disease activity of UC [13-15]. Therefore, we expect IFX to be a promising therapy for small intestinal inflammation associated with UC by its immunomodulative effect, but it should be necessary to perform clinical trial with IFX for a larger number of patients with small-intestinal inflammation associated with UC.

In conclusion, this is the first case of a patient with postoperative occurrence of small intestinal inflammation associated with UC successfully treated with IFX. Most importantly, if we encounter patients with UC who complained of unexplained abdominal pain and diarrhea after undertaking colectomy, we should consider the occurrence of small intestinal inflammation as a differential diagnosis because prompt diagnosis results in excellent outcome. 


\section{References}

1. Thompson JW, Bargen JA: Ulcerative duodenitis and choronic ulcerative colitis: report of two cases. Gastroenterology. 1960; 38: 452-455.

2. Valdez R, Appleman HD, Bronner MP: Diffuse duodenitis associated with ulcerative colitis. Am J surg Pathol. 2000; 24: 1407-1413.

3. Terashima S, Hoshino Y, Kanzaki N, Kogure M, Gotoh M: Ulcerative duodenitis accompanying ulcerative colitis J Clin Gastroenterol. 2001;32:172-175.

4. Ikeuchi H, Hori K, Nishigami T, Nakano H, Uchino M, Nakamura M, Kaibe N, Noda M, Yanagi H, Yamamura T: Diffuse gastroduodenitis and pouchitis asociated with ulcerative colitis. World J Gastroenterol. 2006; 12: 5913-5915.

5. Kawai K, Watanabe T, Nakayama H, Roberts-Thomson I, Nagawa H:

. Image of interest. Gastrointestinal: small bowel inflammation and ulcerative colitis.

J Gastroenterol Hepatol. 2005; 20: 1791.

6. Bell AJ, Price AB, Forbes A, Ciclitira PJ, Groves C, Nicholls RJ: Pre-pouch ileitis: a disease of the ileum in ulcerative colitis after restorative panctocolectomy. Colorectal Dis. 2006; 8: 402-410.

7. Rubenstein J, Sherif A, Appelman H, Chey WD: Ulcerative colitis associated enteritis: is ulcerative colitis always confined to the colon? J Clin Gastroenterol. 2004; 
38: 46-51.

8. Hori K, Ikeuchi H, Nakano H, Uchino M, Tomita T, Ohda Y, Hida N, Matsumoto T,

Fukuda Y, Miwa H: Gastroduodenitis associated with ulcerative colitis. J Gastroenterol.

2008; 43: 193-201.

9. Gooding IR, Springall R, Talbot IC, Silk DB: Idiopathic small-intestinal inflammation after colectomy for ulcerative colitis. Clin Gastroenterol Hepatol. 2008; 6: 707-709.

10. Kohn A, Daperno M, Armuzzi A, Cappello M, Biancone L, Orlando A, Viscido A, Annese V, Riegler G, Meucci G, Marrollo M, Sostegni R, Gasbarrini A, Peralta S, Prantera C: Infliximab in severe ulcerative colitis: short-term results of different infusion regimens and long-term follow-up. Alimentary pharmacology and Therapeutics. 2007; 6: 747-756.

11. Rutgeerts P, Sandborn WJ, Feagan BG, Reinisch W, Olson A, Johanns J, Travers S, Rachmilewitz D, Hanauer SB, Lichtenstein GR, de Villiers WJ, Present D, Sands BE, Colombel JF: Infliximab for induction and maintenance therapy for ulcerative colitis. N Engl J Med. 2005; 353: 2462-2476. 
12. ten Hove T, van Montfrans C, Peppelenbosch MP, van Deventer SJ: Infliximab treatment induces apotosis of lamina propria T lymphocytes in Crohn's disease. Gut. 2002 ; 50: 206-211.

13. Kasahara K, Nakase H, Uza N, Ueno S, Matsuura M, Mikami S, Inoue S, Chiba T: Administration of PEG-interferon to a patient with ulcerative colitis and chronic hepatitis $\mathrm{C}$ correlated with reduced colonic inflammation and reversal of peripheral Th1/Th2 ratios. Case Reports in Gastroenterology. 2007;1:157-161.

14. Matsumura K, Nakase H, Yamamoto S, Yoshino T, Takeda Y, Kasahara K, Ueno S, Uza N, Chiba T: Modulation of the Th1/Th2 balance by infliximab improves hyperthyroidism associated with flare-up of ulcerative colitis. Inflamm Bowel Dis. 2008 [Epub ahead of print]

15. Takeda Y, Nakase H, Namba K, Inoue S, Ueno S, Uza N, Chiba T. Up-regulation of T-bet and tight junction molecules by Bifidobactrium longum improves colonic inflammation of ulcerative colitis. Inflamm Bowel Dis (in press)

16. Shen B, Wu H, Lopez R, Shen L, Fazio V. Diagnostic value of esophagogastroduodenoscopy in patients with ileal pouch-anal anastomosis, Inflamm Bowel Dis. 2009; 15: 395-401 


\section{Figure 1}

A

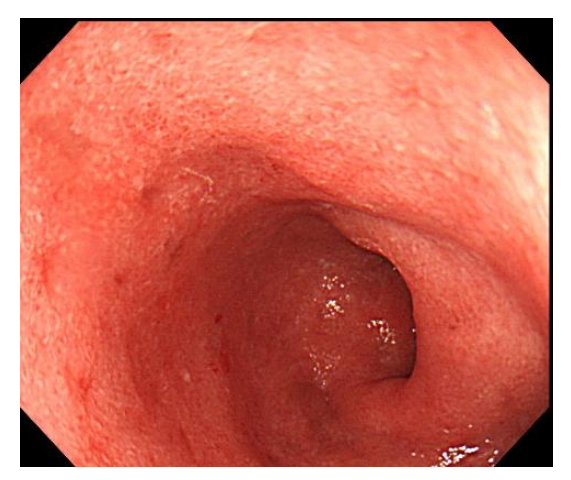

C

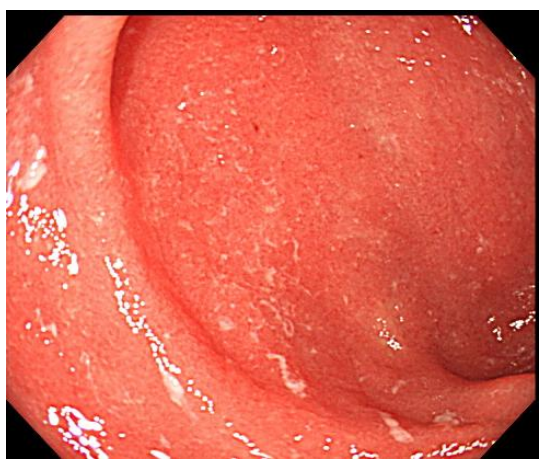

B

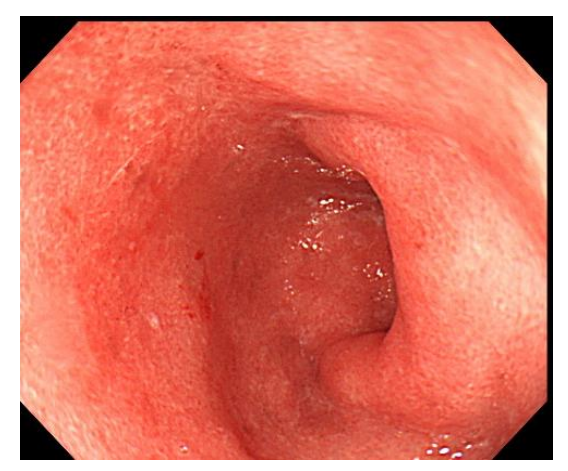

Figure 2

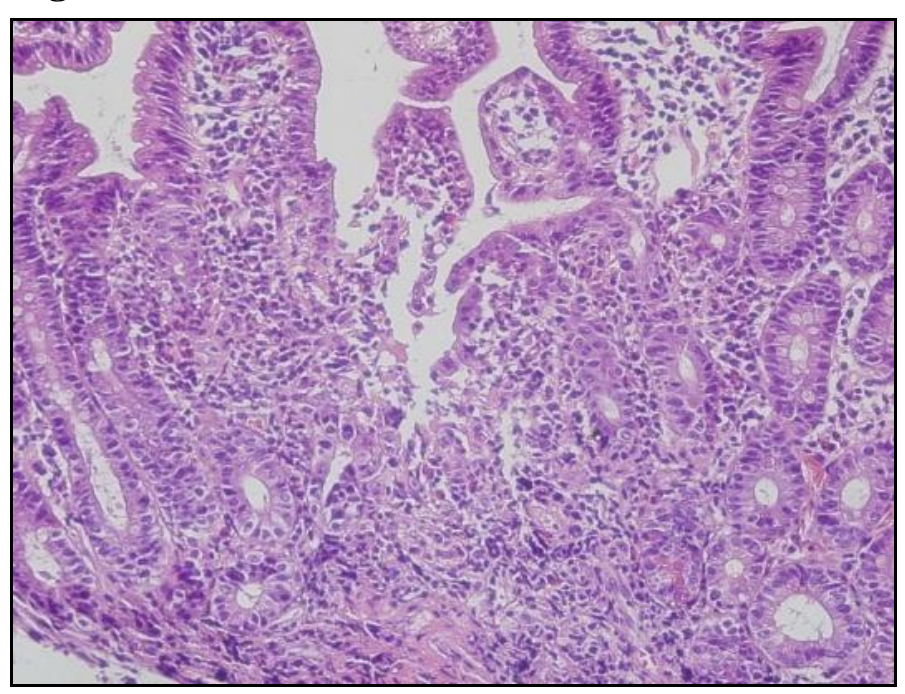


Figure 3

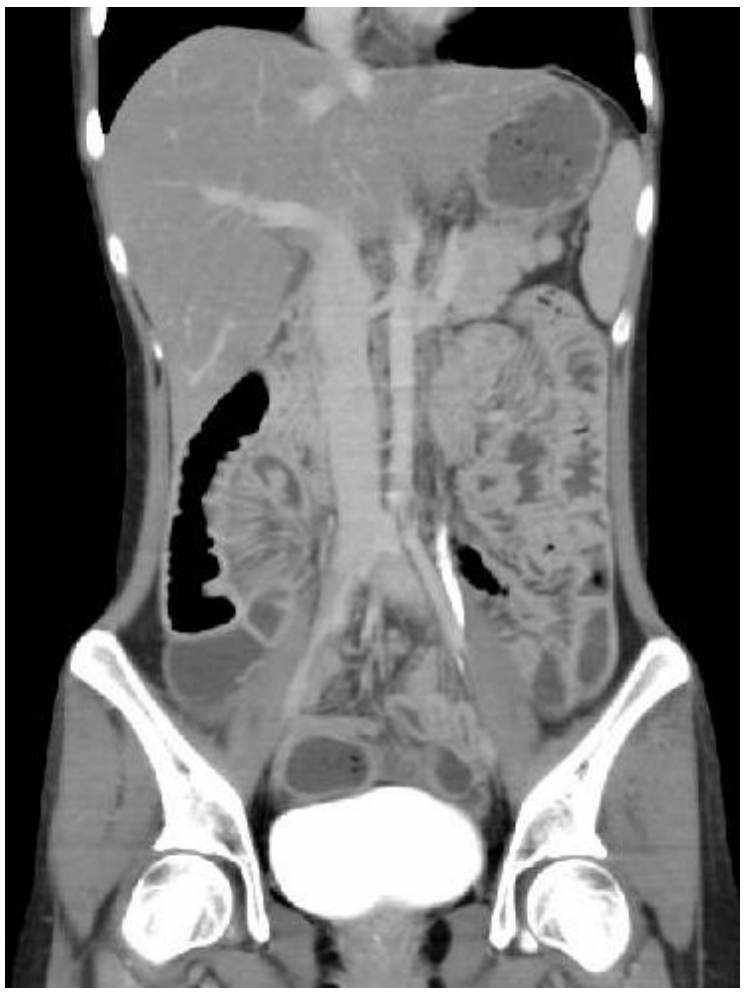

Figure 4

A

B
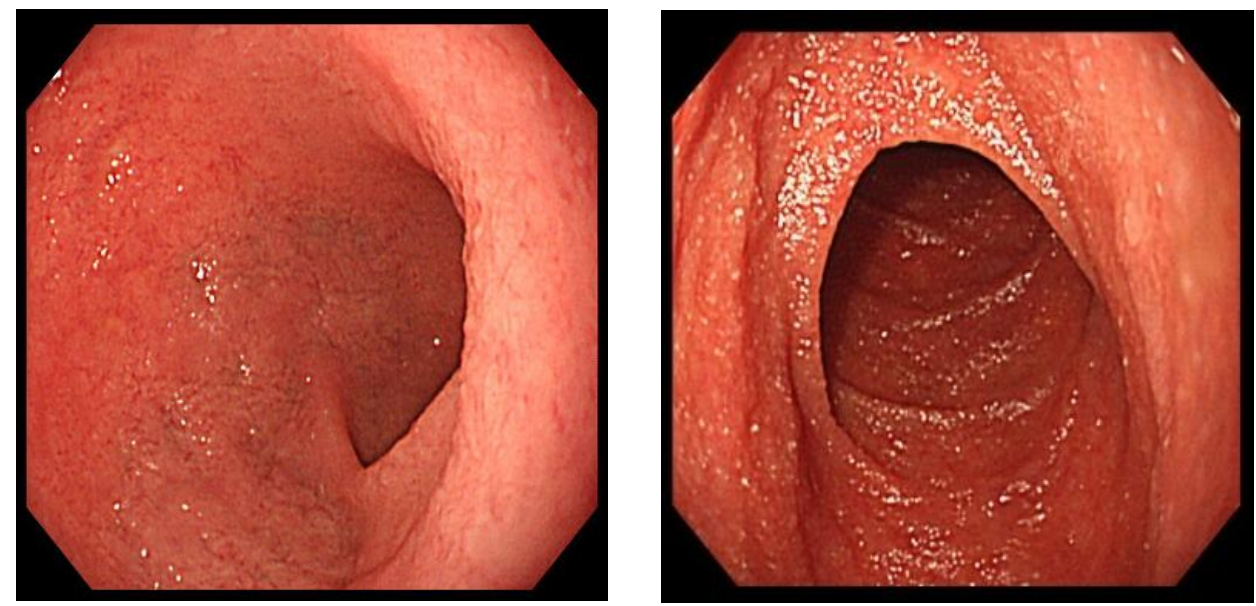


\section{Figure legends}

Figure 1: Esophago-gastro-duodenoscopy disclosed edema, granularity in the duodenal bulb (A, B) and the second portion of duodenum (C).

Figure 2: Histological examination taken from the duodenum showed neutrophil infiltration in the submucosa and cryptisis with no findings of non-caseous granuloma.

Figure 3: Abdominal CT revealed the marked distention and wall thickening and edema of whole small intestine

Figure 4: Esophago-gastro-duodenoscopy performed at 109 days after infliximab treatment revealed significant improvement of duodenitis both in the duodenal bulb (A) and the second portion of duodenum (B). 